[4] Hochman JR et al. Neuropathic pain symptoms in a community knee OA cohort. Osteoarthritis Cartilage. 2011 Jun;19(6):647-54.
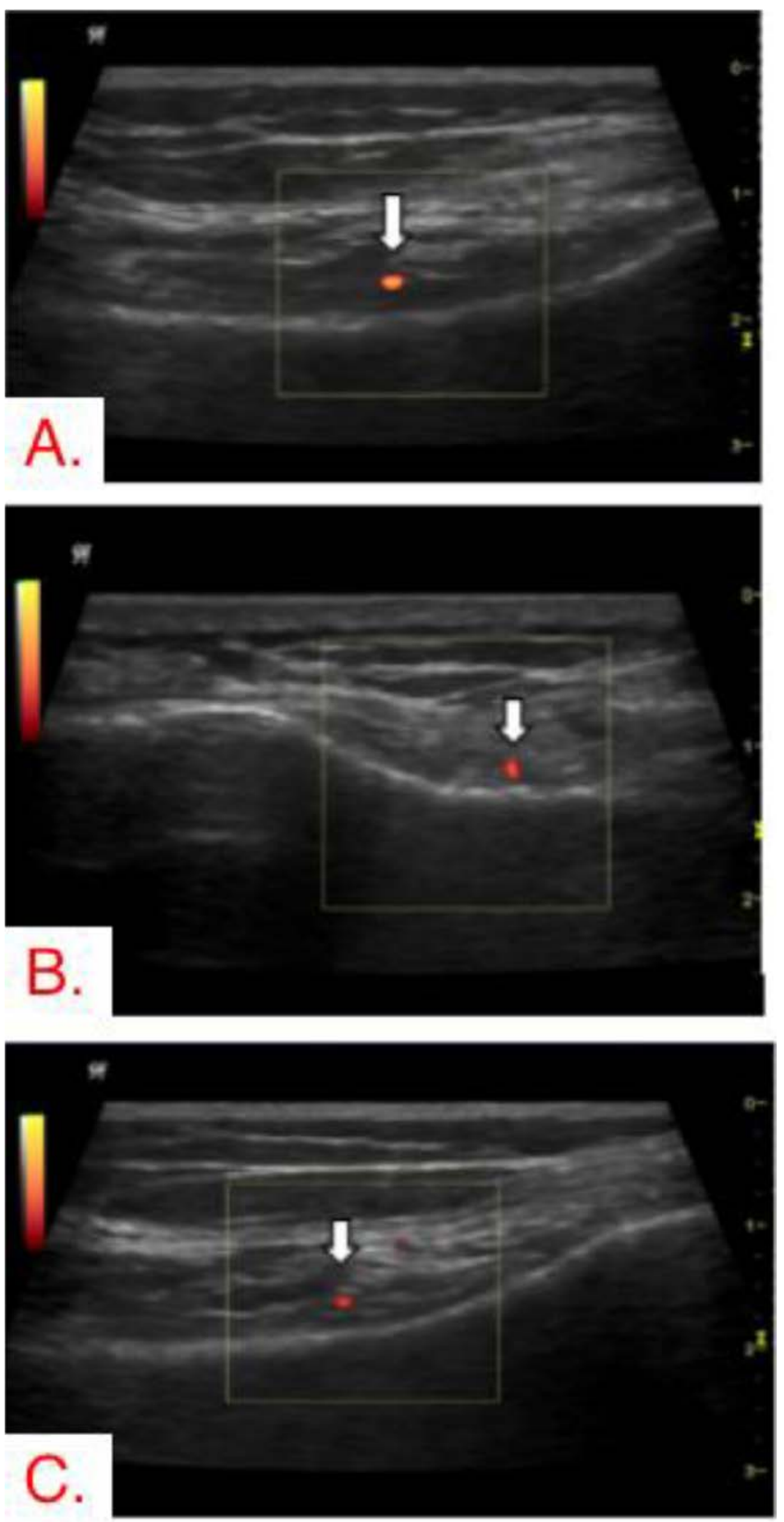

Fig. 1: Ultrasound- guided identification of GNB target sites. Doppler mode. White arrows indicate genicular arteries. A. Superior medial genicular artery. B. Inferior medial genicular artery. C. Superior lateral genicular artery.

Disclosure of Interests: None declared

DOI: 10.1136/annrheumdis-2020-eular.4628

\section{FRI0383 A RANDOMISED PLACEBO-CONTROLLED CLINICAL TRIAL OF CURCUMA LONGA EXTRACT FOR TREATING SYMPTOMS AND EFFUSION-SYNOVITIS OF KNEE OSTEOARTHRITIS (CURKOA TRIAL)}

B. Antony ${ }^{1}$, Z. Wang ${ }^{1}$, T. Winzenberg ${ }^{1}$, G. Cai ${ }^{1}$, L. Laslett ${ }^{1}$, D. Aitken ${ }^{1}$, I. Hopper ${ }^{2}$, A. Singh ${ }^{1}$, R. Jones ${ }^{3}$, J. Fripp ${ }^{4}$, C. Ding ${ }^{1}$, G. Jones ${ }^{1} .{ }^{1}$ University of Tasmania, Menzies Institute for Medical Research, Hobart, Australia; ${ }^{2}$ Monash University, Department of Epidemiology and Preventive Medicine, School of Public Health and Preventive Medicine, Melbourne, Australia; ${ }^{3}$ Royal Hobart Hospital, Department of Radiology, Hobart, Australia; ${ }^{4}$ University of Queensland, Biomedical Informatics \& Imaging Group, CSIRO Health and Biosecurity, The Australian e-Health Research Centre, Brisbane, Australia
Background: Pharmacological therapies are limited, associated with off-target effects, are frequently contraindicated, and only modestly effective for pain in osteoarthritis (OA). Effusion and synovitis are common in OA and are associated with symptomatic and structural progression of OA. Curcuma longa (Turmeric) extract has anti-inflammatory effects and is gaining popularity in the treatment of $\mathrm{OA}$ despite the lack of high-quality evidence.

Objectives: The CurKOA trial aimed to determine the efficacy of Curcuma longa extract for reducing knee symptoms and effusion-synovitis in patients with symptomatic knee OA and knee effusion-synovitis.

Methods: In this randomised, double-blind, placebo-controlled trial, participants with significant knee pain ( $\geq 40 \mathrm{~mm}$ on a $100-\mathrm{mm}$ visual analog scale [VAS]), symptomatic knee OA (by ACR criteria) and ultrasound defined effusion-synovitis were randomised to receive Curcuma longa extract $(80 \%$ aqueous based extract standardized to turmerosaccharides $+20 \%$ curcuminoids, $2 \times 500 \mathrm{mg}$ capsules day) or identical placebo for 12 weeks. Knee MRI scans were obtained at baseline and 12 weeks. Coprimary outcomes were changes in knee pain assessed by VAS and change in knee effusion-synovitis volume assessed by MRI over 12 weeks.

Results: Among 70 participants (36 received Curcuma longa, 34 received placebo, age $61.8 \pm 8.6$ years, $56 \%$ female), Curcuma longa significantly improved VAS knee pain compared to placebo $(-9.11 \mathrm{~mm}, 95 \%$ confidence interval $[\mathrm{Cl}]$ [- 17.79 to -0.44$]$ ) over 12 weeks, equivalent to a standardised effect size of 0.50 . There was no significant between group difference in change in effusion-synovitis volume $(3.24 \mathrm{~mL}[-0.33,6.82])$. There were significantly greater reductions in WOMAC knee pain $(-47.22 \mathrm{~mm}[-81.22,-13.22])$, WOMAC function $(-112.26 \mathrm{~mm}$ [-222.79 to -1.74$])$ and significantly more OARSI-OMERACT treatment responders $(63 \%$ treatment vs. $38 \%$ placebo [Risk Ratio $=1.64(1.00$ to 2.70$)]$ ]) in the Curcuma longa group compared to the placebo group. There was no significant between-group difference in lateral femoral cartilage T2 relaxation time $(-0.38 \mathrm{~ms}$ [- 1.10 to 0.34$])$ assessed from compositional MRI. The incidence of adverse events was similar in the Curcuma longa $(n=14(39 \%))$ and placebo $(n=18$ $(53 \%))$ groups over 12 weeks $(P=0.24)$.

Conclusion: An extract of Curcuma longa significantly improved knee pain in an inflammatory phenotype of knee OA patients over 12 weeks compared to placebo but had no effect on knee effusion-synovitis and cartilage composition assessed using MRI. The moderate effect size of the treatment supports the use of Curcuma longa extract for the symptomatic management of knee OA.
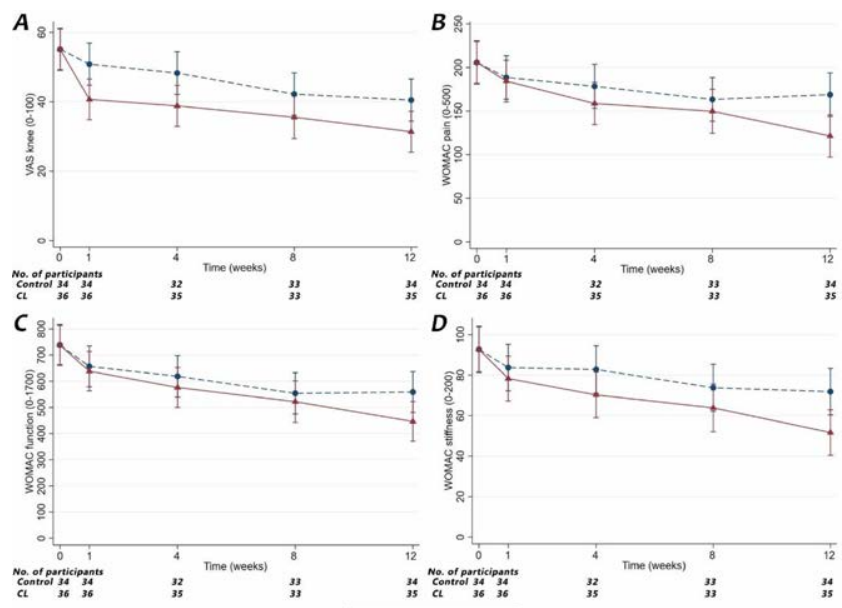

Figure 1. Change in VAS and WOMAC subscale scores in treatment and control groups over the course of the study. (VAS = Visual analog scale, WOMAC = Western Ontario and McMaster University Index, $\mathrm{CL}=$ Curcuma longa extract)

Disclosure of Interests: None declared DOI: 10.1136/annrheumdis-2020-eular.5139

\section{FRI0384 BODY COMPOSITION AS A MEDIATOR IN THE RELATIONSHIP BETWEEN PHYSICAL ACTIVITY AND PHYSICAL FUNCTION IN LOWER-LIMB OSTEOARTHRITIS: RESULTS FROM THE KHOALA COHORT}

M. Wieczorek ${ }^{1,2}$, C. Rotonda ${ }^{1,3}$, J. Sellam ${ }^{4}$, F. Guillemin ${ }^{1,5}$, A. C. Rat ${ }^{1,6}$ ${ }^{1}$ Université de Lorraine, EA 4360 APEMAC, Nancy, France; ${ }^{2}$ University Hospital Zurich, Waid City Hospital, Centre on Aging and Mobility, and University of Zurich, Zurich, Switzerland; ${ }^{3}$ Université de Lorraine, Centre Pierre Janet, 